\title{
Homotypic Interaction of Stabilin-2 Plays a Critical Role in Lymph Node Metastasis of Tongue Cancer
}

\author{
MYUNG WOUL HAN ${ }^{1}$, JONG CHEOL LEE ${ }^{1}$, SEUNG-YOON PARK ${ }^{2}$, YOUNG MIN KIM ${ }^{3}$, KYUNG-JA CHO ${ }^{4}$, \\ SEONG WHO KIM ${ }^{5}$, MYUNGJIN LEE ${ }^{6}$, SOON YUHL NAM ${ }^{6}$, IN-SAN KIM ${ }^{7}$ and SANG YOON KIM ${ }^{6}$ \\ Departments of ${ }^{1}$ Otolaryngology, and ${ }^{3}$ Pathology, Ulsan University Hospital, \\ University of Ulsan College of Medicine, Ulsan, Republic of Korea; \\ ${ }^{2}$ Department of Biochemistry, School of Medicine, Dongguk University, Gyeongju, Republic of Korea; \\ Departments of ${ }^{4}$ Pathology, ${ }^{5}$ Biochemistry and Molecular Biology, and ${ }^{6}$ Otolaryngology, \\ Asan Medical Center, University of Ulsan College of Medicine, Seoul, Republic of Korea; \\ ${ }^{7}$ Korea University-Korea Institute of Science and Technology School, Korea University, Seoul, Republic of Korea
}

\begin{abstract}
Background/Aim: Lymph node (LN) metastasis of solid types of tumors has important clinical significance and it is therefore critical to identify molecular biomarkers that would enable the selection of patients with LN metastases. Patients and Methods: We evaluated the expression of stabilin-2 in primary oral tongue tumors and metastatic LNs using immunohistochemical staining. The correlation between risk factors and nodal metastasis was assessed and disease-free survival was analyzed. Results: Stabilin-2 expression remained a significant predictor of LN metastasis and the factor affecting recurrence in tongue cancer. Most importantly, all metastatic tumors of tongue, lung, stomach and colon cancers stained positive for stabilin-2 and stabilin-2 was expressed strongly in the sinusoidal endothelial cell of metastatic LNs. Conclusion: Stabilin-2 can play a critical role in the first entrapping step of $L N$ metastasis through homotypic interaction with the lymphatic endothelium and appears to be a tumor biomarker predicting for LN metastasis in patients with solid tumors.
\end{abstract}

Lymph node (LN) metastasis of solid tumors, including head and neck cancer, has important clinical significance as it is associated with disease progression and poor prognosis and often determines the choice of therapies (1). The ability to predict LN metastasis can improve patient outcomes and

Correspondence to: Sang Yoon Kim, MD, Ph.D., Department of Otolaryngology, Asan Medical Center, University of Ulsan College of Medicine, 88 Olymhic-Ro 43-Gil, Songpa-Gu, Seoul 138-736, Republic of Korea. Tel: +182230103710 , Fax: +82 24892773, email: sykim2@amc.seoul.kr

Key Words: Stabilin-2, lymph node metastasis, tongue cancer, tumor biomarker, lymphatic endothelial cells. prevent unnecessary treatment. It is, therefore, critical to identify molecular biomarkers that would enable the selection of patients with LN metastases. The increasing recognition of the importance of $\mathrm{LN}$ metastasis in cancer biology has prompted recent studies to elucidate the molecular signals and cellular changes involved in this complex process. Some of these changes include lymphangiogenesis, the expansion of immunosuppressive cells, up-regulation of chemokines and cytokines, and blood vessel remodeling in the LNs (2-4). These events help facilitate tumor cell entry, colonization, and survival in LNs. A growing body of literature suggests that various chemokine-receptor signaling pathways also play a central role in trafficking different cancer cell types to the LNs (5, 6). In a recent study, a role for the chemokine (C-C motif) ligand 1 (CCL1)/chemokine (C-C motif) receptor 8 (CCR8) chemokine-receptor signaling pathway was demonstrated to be important for the entry of melanoma tumor cells into $\mathrm{LN}$ parenchyma (2). However, the question remains how tumor cells are entrapped by LNs.

Stabilin-2 is a large multifunctional glycoprotein expressed predominantly by certain macrophages and the sinusoidal endothelial cells of the spleen, LNs, and liver, and reportedly serves as a hyaluronan receptor in endocytosis, as a scavenger receptor that binds to bacteria, and as a protein that endocytoses modified low-density lipoprotein and the end-products of glycation (7-9). We recently showed that stabilin-2 functions as a membrane phosphatidylserine receptor that is involved in engulfment of apoptotic cells as well as in lymphocyte adhesion to the hepatic sinusoidal endothelium and in hemophilic cell-cell interaction $(8,10$ 17). In addition, stabilin- 2 is reported to be a scavenger receptor for hyaluronic acid, which has been implicated in the proliferation and distant metastasis of melanoma cells (18). However, little is known about its role in LN metastasis 

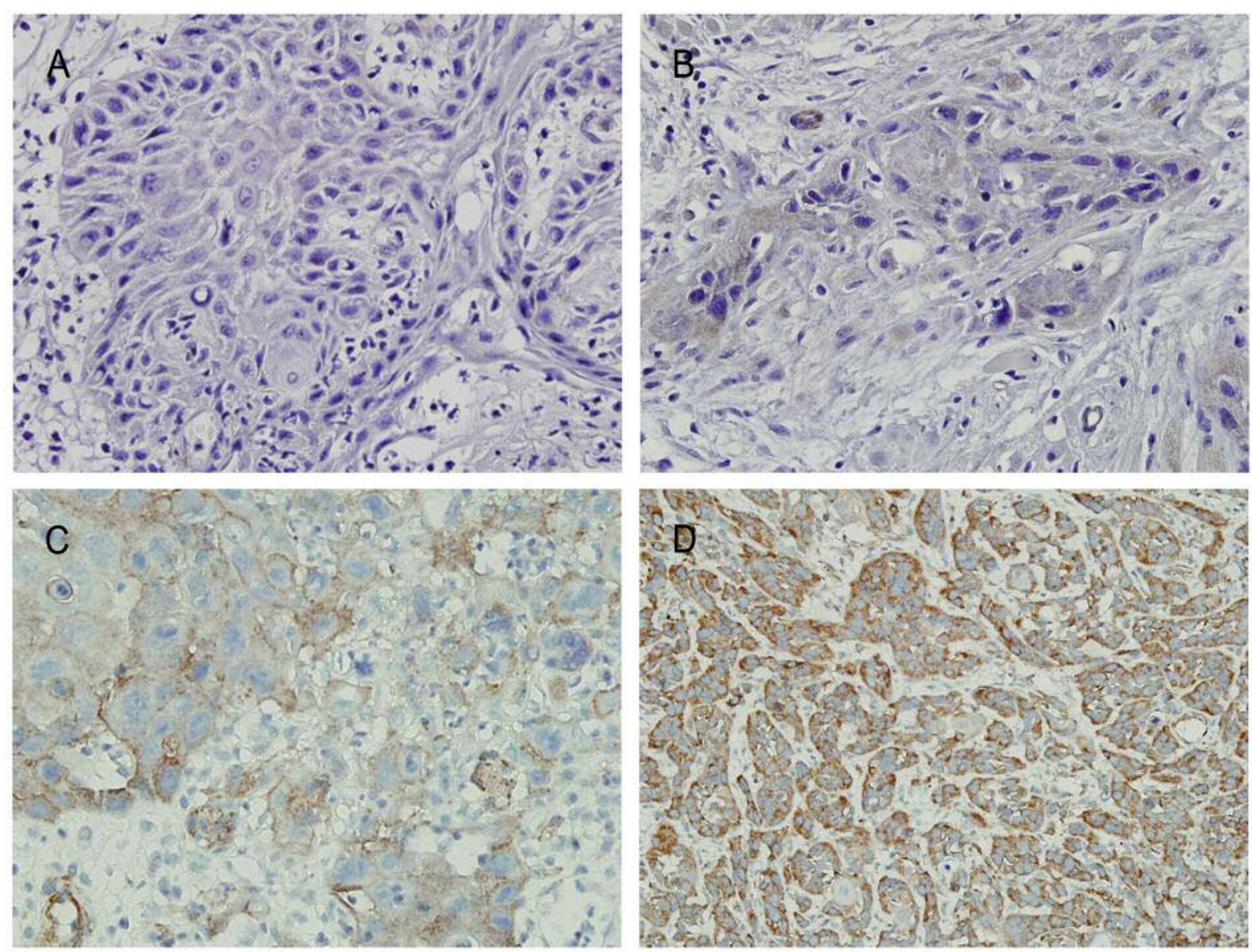

Figure 1. Immunohistochemical study of stabilin-2 in tongue cancer. Staining intensity was graded as negative $(A)$, weak $(B)$, intermediate $(C)$, and strong (D) expression (original magnification $\times 200$ ).

and cancer prognosis in solid tumors including head and neck cancer.

Stabilin-2 is an adhesion molecule and is expressed in the sinusoidal endothelial cells of collecting lymphatic vessels. Based on this information, we hypothesized that stabilin-2 may play a critical role in the first entrapping step of LN metastasis through the homotypic interaction with lymphatic endothelium. Therefore, we investigated the role of stabilin-2 in tongue cancer in relation to $\mathrm{LN}$ metastasis and recurrence. Additionally, we analyzed the correlation between stabilin-2 expression and nodal metastasis in lung, stomach, and colon cancer.

\section{Patients and Methods}

Patients. The medical records of all consecutive patients treated for primary oral tongue cancer at our institution between January 1997 and December 2010 were reviewed. Eligibility criteria included the following: oral tongue cancer, squamous cell carcinoma, and patients who underwent radical surgery and neck dissection as initial treatment. Patients were excluded if they had concurrent second primary malignancies or a history of radiotherapy or treatment of tongue cancer. In total, 99 patients ( 76 men, 23 women; mean age $=53.5$ years, range $=22-78$ years) were enrolled. The following data were recorded from the histopathology reports: histological grade, pTNM stage of primary tumor according to American Joint Committee on Cancer (AJCC) classification, type of neck dissection, resection margin, perineural invasion, lymphovascular invasion, and extranodal extension. All patients underwent neck dissection on the involved side and glossectomy as primary treatment. Fifty-nine patients underwent unilateral and six bilateral selective neck dissection, 28 patients had unilateral and six bilateral modified radical neck dissection. Postoperative radiotherapy was performed in 43 patients. Ten cases each of lung, stomach, and colon cancer were also analyzed. All tumors were adenocarcinomas. Patient data were reviewed retrospectively after receiving approval from the Institutional Review Board of Asan Medical Center (2013-0770).

Immunohistochemical analysis. For immunohistochemical evaluation, paraffin-embedded biopsy specimens were retrieved from our pathology archives and tissue arrays of primary tumor and slide sections of metastatic $\mathrm{LN}$ were constructed using formalin-fixed tumor blocks. Regions of each primary tumor were chosen under microscopy 

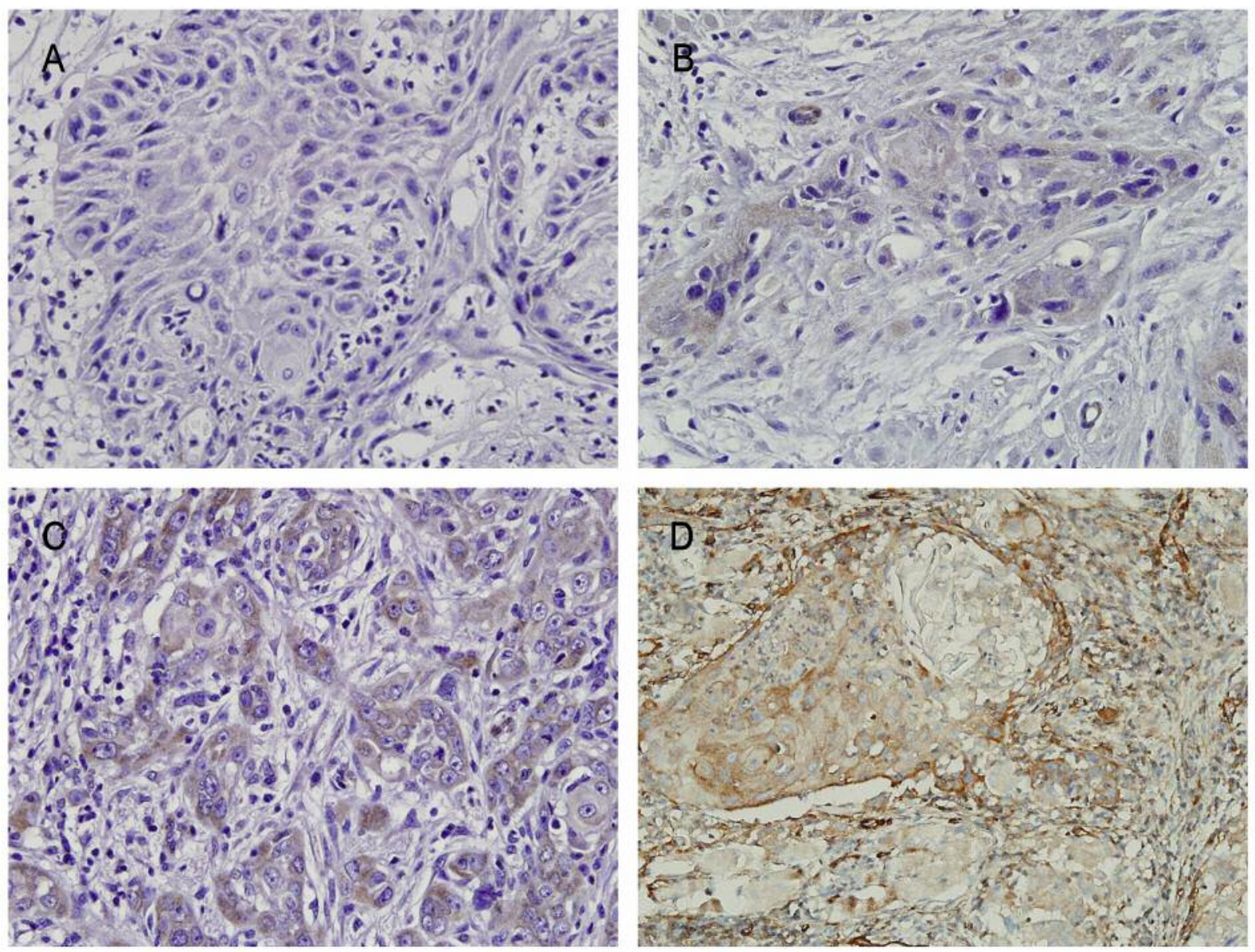

Figure 2. Immunohistochemical study of stabilin-2 in tongue cancer. Immunoreactivity, was determined by the percentage of positive cells with negative specimens having $<5 \%$ positive cells $(A), 5-10 \%$ positive cells $=1(B), 11-30 \%=2,31-50 \%=3,51-80 \%=4(C)$, and $>80 \%$ positive cells $=5$ (D) (original magnification $\times 200$ ).

and arranged pair-wise in tissue microarray blocks. The invasive front of each tumor was represented by two validated tissue cores on a tissue microarray. After deparaffinization and rehydration, $4-\mu \mathrm{m}$ thick sections were subjected to heat-induced antigen retrieval using a 0.01 $\mathrm{M}$ citrate buffer $(\mathrm{pH}$ 6.0) for 1 hour. Sections were incubated in aqueous $3 \% \mathrm{H}_{2} \mathrm{O}_{2}$ for 15 minutes to quench endogenous peroxidase activity and then washed with $1 \times$ phosphate-buffered saline (PBS). Slides were loaded into a humid chamber and blocked for 30 min with 1× Universal Blocking Agent $\left(10 \times\right.$ Power Block $^{\mathrm{TM}}$ : BioGenex Laboratories, San Ramon, CA, USA) before incubation overnight at $4^{\circ} \mathrm{C}$ with primary antibodies against stabilin-2 (1:100; Sigma-Aldrich Co. LLC., St. Louis, MO, USA). The next day, slides were incubated for 1 hour at room temperature and then treated with EnVision Reagent (Dako REAL ${ }^{\mathrm{TM}}$ EnVision $^{\mathrm{TM}}$, Glostrup, Denmark) for 30 min. Slides were washed with PBS and treated with the chromogen 3,3'diaminobenzidine for $15 \mathrm{~min}$ to allow the formation of a brown reaction product. The slides were counterstained with Mayer's hematoxylin, dehydrated in graded alcohol, cleared in xylene, and mounted. The slides were independently interpreted by two reviewers with no knowledge of the clinical data. Immunostaining was graded by the immunoreactivity score (IRS), which reflects staining intensity
(SI), assessed to be negative $(=0)$, weak $(=1)$, moderate $(=2)$, or strong $(=3)$; and reactivity, determined by the percentage of positive cells (PP), with negative specimens having $<5 \%$ positive cells, $5-10 \%$ positive cells $=1,11-30 \%=2,31-50 \%=3,51-80 \%=4$, and $>80 \%$ positive cells $=5$. The IRS was calculated by multiplying SI by PP, giving a minimum score of 0 and a maximum score of 15 . In addition to the IRS, expression patterns were assessed. For each patient, two samples were stained and the average IRS was used for statistical analysis (Figures 1 and 2). Staining for stabilin-2 was then individually defined as low $(I R S=0-4)$, moderate (IRS=5-9), or high $(I R S=10-15)$.

Statistical analysis. In order to determine statistically significant relationships between the distribution of categorical values, the chisquare test, Fisher's exact test, and multiple logistic regression analysis were used as appropriate. Disease-free survival (DFS) rates were calculated by the Kaplan-Meier method and multivariate analysis was performed by Cox regression analysis using variables shown to be significant in univariate analysis. All analyses were performed using Statistical Package for the Social Sciences (SPSS) Version 12 software (SPSS Inc., Chicago, IL, USA) and $p$-values less than 0.05 were considered to be statistically significant. 
Table I. Patient characteristics and tumor features of the tongue cancer study population $(N=99)$.

\begin{tabular}{|c|c|}
\hline & Value \\
\hline \multicolumn{2}{|l|}{ Gender, n (\%) } \\
\hline Male & $76(77.2)$ \\
\hline Female & $23(22.8)$ \\
\hline Age, years & $53.5(22-78)$ \\
\hline \multicolumn{2}{|l|}{ Histological grade, $\mathrm{n}(\%)$} \\
\hline Well differentiated & $65(64.4)$ \\
\hline Moderately differentiated & $26(26.7)$ \\
\hline Poorly differentiated & $8(7.9)$ \\
\hline \multicolumn{2}{|l|}{$\mathrm{T}$ Classification, n (\%) } \\
\hline $\mathrm{T} 1$ & $39(35.6)$ \\
\hline $\mathrm{T} 2$ & $39(40.6)$ \\
\hline $\mathrm{T} 3$ & $3(3.0)$ \\
\hline $\mathrm{T} 4 \mathrm{a}$ & $18(20.8)$ \\
\hline \multicolumn{2}{|l|}{ Nodal classification, n (\%) } \\
\hline N0 & $51(51.6)$ \\
\hline N1 & $24(25.3)$ \\
\hline $\mathrm{N} 2 \mathrm{a}$ & $1(1.0)$ \\
\hline $\mathrm{N} 2 \mathrm{~b}$ & $21(20.0)$ \\
\hline $\mathrm{N} 2 \mathrm{c}$ & $2(2.1)$ \\
\hline \multicolumn{2}{|l|}{ AJCC stage, n (\%) } \\
\hline I & $28(27.4)$ \\
\hline II & $16(15.8)$ \\
\hline III & $22(22.1)$ \\
\hline IV & $32(34.7)$ \\
\hline \multicolumn{2}{|l|}{ Stabilin-2 expression } \\
\hline \multicolumn{2}{|l|}{ Staining intensity, n (\%) } \\
\hline Negative & $14(14.1)$ \\
\hline Weak & $56(56.6)$ \\
\hline Moderate & $12(12.1)$ \\
\hline Strong & $17(17.2)$ \\
\hline \multicolumn{2}{|l|}{ Staining reactivity, n (\%) } \\
\hline $0(<5 \%)$ & $35(35.3)$ \\
\hline $1(5-10 \%)$ & $16(16.2)$ \\
\hline $2(11-30 \%)$ & $14(14.1)$ \\
\hline $3(30-50 \%)$ & $18(18.2)$ \\
\hline $4(50-80 \%)$ & $14(14.1)$ \\
\hline $5(>80 \%)$ & $2(2.0)$ \\
\hline \multicolumn{2}{|l|}{ IRS grade, n (\%) } \\
\hline Low (IRS 0-4) & $72(61.1)$ \\
\hline Moderate (IRS 5-9) & $19(35.8)$ \\
\hline High (IRS 10-15) & $8(3.1)$ \\
\hline
\end{tabular}

AJCC: American Joint Committee on Cancer, IRS: immunoreactivity score.

\section{Results}

Correlation of stabilin-2 expression and LN metastasis. Patient characteristics and tumor features of the patients with tongue cancer are shown in Table I. The majority of tumors (64.4\%) were well differentiated. Seventy-eight patients $(76.2 \%)$ had early primary tumors $(\mathrm{T} 1, \mathrm{~T} 2)$ and $21(23.8 \%)$ had advanced tumors (T3, T4). Fifty-one patients $(51.6 \%)$ were negative and $48(48.4 \%)$ were positive for nodal involvement. Fifty-four patients $(56.8 \%$ ) had advanced tumors (AJCC stage III, IV).
Table II. Correlation between clinical variables and nodal metastasis in tongue cancer $(N=99)$.

\begin{tabular}{|c|c|c|c|}
\hline Variable & $\begin{array}{c}\text { pN0 } \\
(\mathrm{N}=51) \\
\text { No. }\end{array}$ & $\begin{array}{c}\mathrm{pN}+ \\
(\mathrm{N}=48) \\
\text { No. }\end{array}$ & $p$-Value* \\
\hline \multicolumn{4}{|l|}{ Age } \\
\hline$<65$ Years $(\mathrm{N}=75)$ & 36 & 39 & 0.247 \\
\hline$\geq 65$ Years $(\mathrm{N}=24)$ & 15 & 9 & \\
\hline \multicolumn{4}{|l|}{ Histological grade } \\
\hline Well diff. $(\mathrm{N}=65)$ & 38 & 27 & 0.061 \\
\hline Moderately \& poorly diff. ( $\mathrm{N}=34)$ & 13 & 21 & \\
\hline \multicolumn{4}{|l|}{ Depth of invasion } \\
\hline$<4 \mathrm{~mm}(\mathrm{~N}=21)$ & 15 & 6 & 0.050 \\
\hline$\geq 4 \mathrm{~mm}(\mathrm{~N}=78)$ & 36 & 42 & \\
\hline \multicolumn{4}{|l|}{ T Stage } \\
\hline Early $(\mathrm{T} 1, \mathrm{~T} 2, \mathrm{~N}=78)$ & 45 & 33 & 0.026 \\
\hline Advanced (T3,T4a, N=21) & 6 & 15 & \\
\hline \multicolumn{4}{|l|}{ Stabilin-2 intensity } \\
\hline Negative (negative, low, N=70) & 43 & 27 & 0.004 \\
\hline Positive (moderate, strong, $\mathrm{N}=29$ ) & 8 & 21 & \\
\hline \multicolumn{4}{|l|}{ Stabilin-2 reactivity } \\
\hline Negative $(<5 \%, \mathrm{~N}=35)$ & 24 & 11 & 0.020 \\
\hline Positive ( $\geq 5 \%, N=64)$ & 27 & 37 & \\
\hline \multicolumn{4}{|l|}{ Stabilin-2 IRS grade } \\
\hline Negative (low, $\mathrm{N}=72$ ) & 44 & 28 & 0.003 \\
\hline Positive (moderate, high, $\mathrm{N}=27$ ) & 7 & 20 & \\
\hline
\end{tabular}

IRS: Immunoreactivity score, Diff.: differentiated. *Fisher's exact test.

Stabilin-2 immunohistochemical staining was of moderate/ strong intensity in 29 cases, whereas weak/negative immunostaining was noted in 70 cases. According to the IRS score, 27 cases were positive (a moderate or high score) for stabilin-2, whereas negative immunostaining (a low score) was noted in 72 cases (Table I).

The relationship between pathological and immunohistochemical factors and the risk of cervical metastasis was assessed. In univariate analysis, advanced tumor stage was found to correlate with positive $\mathrm{LN}$ status $(p=0.026$, Table II), and depth of invasion and stabilin-2 expression (intensity, reactivity, and IRS grade) were significantly associated with nodal metastasis $(p=0.050, p=0.004, p=0.020$, and $p=0.003$, respectively). Stabilin-2 intensity and reactivity were excluded from multivariate analysis because the IRS grade included the status of intensity and reactivity. After multivariate analysis, only stabilin-2 expression remained a significant predictor of $\mathrm{LN}$ metastasis of tongue cancer (Table III).

Expression of stabilin-2 in 36 metastatic LNs was investigated. We found that the metastatic lesions were observed at only sinusoidal endothelial cells of one $\mathrm{LN}$ which is at the junction of the collecting lymphatic vessel and represents a barrier for entry of tumor cells into the LN at the 

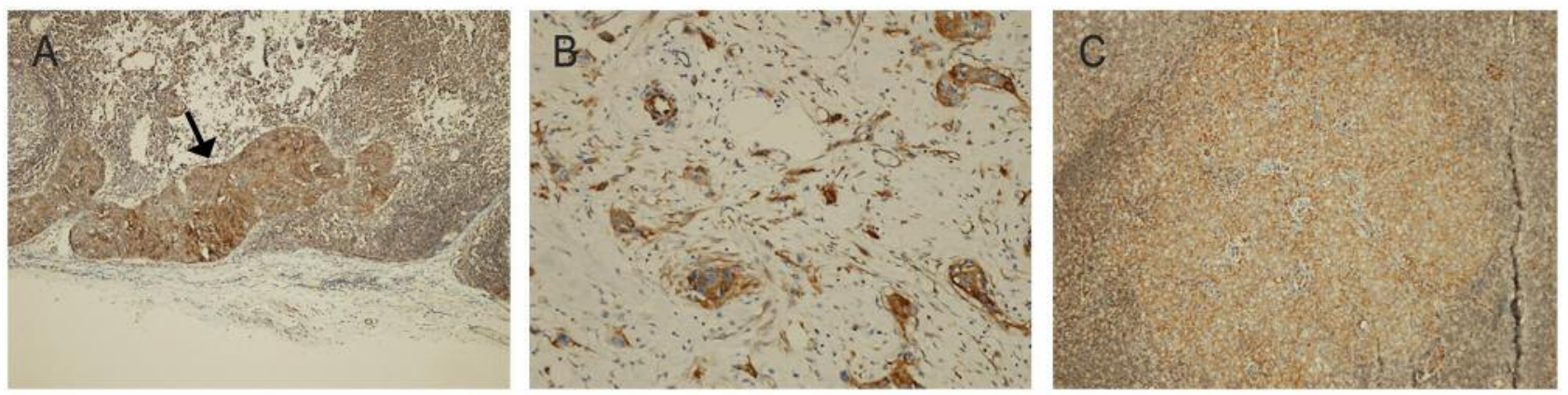

Figure 3. The metastatic lesions were observed only at sinusoidal endothelial cells (arrow) of lymph nodes and stabilin-2 was expressed strongly in the sinusoidal endothelial cells of metastatic lymph nodes $(A ; \times 100)$. Immunohistochemical study of stabilin-2 in metastatic lymph nodes. Staining intensity was graded as weak, intermediate $(B)$, and strong $(C)$ (original magnification $\times 200)$.
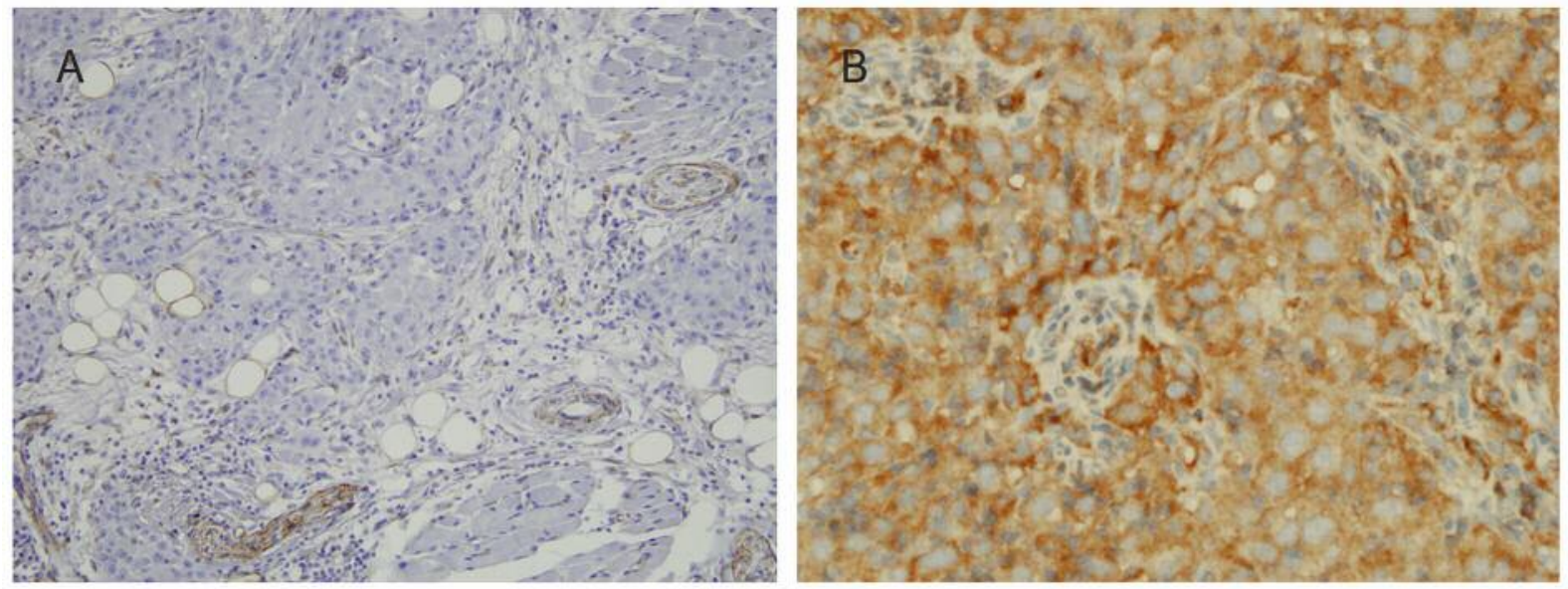

Figure 4. A poorly-differentiated squamous cell carcinoma in the left tongue mucosa of a 78-year-old woman. On immunohistochemistry, the primary tumor had negative expression for stabilin-2 $(A ; \times 200)$, but the metastatic lymph node of this patient showed strong expression of stabilin-2 (B; $\times 400)$.

Table III. Multivariate analysis of clinical variables associated with nodal metastasis in tongue cancer.

\begin{tabular}{lccc}
\hline Variable & OR & $95 \%$ CI & $p$-Value \\
\hline T Stage (early $v s$. advanced) & 2.034 & $0.640-6.465$ & 0.229 \\
Depth of invasion $(<4 \mathrm{~mm} v s . \geq 4 \mathrm{~mm}$ ) & 2.689 & $0.891-8.115$ & 0.079 \\
Stabilin-2 expression (low $v$ s. moderate \& high) & 3.444 & $1.194-9.937$ & 0.022 \\
\hline
\end{tabular}

OR: Odds ratio, CI: confidence interval.

stage of tumor micrometastasis. Stabilin-2 was found to be expressed strongly in the sinusoidal endothelial cell of the metastatic LN (Figure 3A). All metastatic foci of LNs exhibited positive staining for stabilin-2 and immunohistochemical staining was of moderate/strong intensity in 17 cases and weak in 19 cases, respectively (Figure 3B and 3C). But there was no correlation between stabilin-2 expression (staining intensity) of primary tumor and that of metastatic LNs $(p=0.281$, data not shown). Data for a representative patient are shown in Figure 4. This patient had a poorly differentiated squamous cell carcinoma in the left tongue mucosa, and the primary tumor had negative expression for stabilin-2. However, the metastatic lymph node of this patient showed strong expression of stabilin-2. 
Table IV. Correlation between stabilin-2 expression and lymph node metastasis in lung, stomach, and colon cancer.

\begin{tabular}{lccc}
\hline Variable & $\mathrm{pN} 0(\mathrm{~N}=18)$ & $\mathrm{pN}+(\mathrm{N}=12)$ & $p$-Value* \\
\cline { 2 - 4 } & $\begin{array}{c}\text { No. of } \\
\text { patients }\end{array}$ & $\begin{array}{c}\text { No. of } \\
\text { patients }\end{array}$ & \\
& & & \\
\hline Stabilin-2 intensity & 12 & 3 & 0.023 \\
$\quad$ Negative (negative, low) & 6 & 9 & \\
$\quad$ Positive (moderate, strong) & & & \\
Stabilin-2 reactivity & 7 & 1 & 0.050 \\
$\quad$ Negative (<5\%) & 11 & 11 & \\
$\quad$ Positive ( $\geq 5 \%)$ & & & \\
Stabilin-2 IRS grade & 12 & 4 & 0.071 \\
$\quad$ Negative (low) & 6 & 8 & \\
Positive (moderate, high) & 6 &
\end{tabular}

IRS: Immunoreactivity score. *Fisher's exact test.

In addition, we found that stabilin-2 expression (particularly staining intensity and immunoreactivity) was significantly associated with nodal metastasis in lung, stomach, and colon cancer on univariate analysis, although our sample size was small (Table IV). Moreover, all metastatic foci of $12 \mathrm{LNs}$ in these patients stained positively for stabilin-2, same as metastatic LNs of tongue cancer and immunohistochemical staining was of moderate/strong intensity in nine cases and weak immunostaining was noted in three cases, respectively (data not shown).

Stabilin-2 expression and clinical outcome. The mean follow-up period for the whole patient cohort was 96.3 months (range=6-149 months). Among the 99 patients with tongue cancer, 28 presented with locoregional recurrence and six with distant metastasis. The five-year DFS for all patients was $61.7 \%$. Univariate analysis showed that cell differentiation $(p=0.017)$, nodal classification $(p=0.011)$, extranodal extension ( $p=0.0035)$, and stabilin-2 expression were significantly associated with DFS (Table V). However, on multivariate analysis, nodal classification and stabilin-2 expression were significantly correlated with DFS (Table VI; $p=0.05$ and $p=0.045$ )

\section{Discussion}

LN metastases are indicative of poor prognosis, but the mechanisms of tumor cell dissemination via the lymphatics are poorly understood. It has been widely believed that tumor cells enter the LNs passively with the flow of lymph, but Das et al. recently demonstrated that the entry of tumor cells into a $\mathrm{LN}$ requires active cell migration, and they also identified the lymphatic endothelium of the LN subcapsular sinus as a critical gatekeeper. In addition, they demonstrated that
Table V. Results of univariate analysis exploring disease-free survival in tongue cancer $(N=95)$.

\begin{tabular}{|c|c|c|}
\hline & $\begin{array}{c}\text { 5-Year } \\
\text { disease-free } \\
\text { survival }\end{array}$ & $p$-Value \\
\hline \multicolumn{3}{|l|}{ Age } \\
\hline$<65$ Years $(\mathrm{N}=75)$ & $64.1 \%$ & 0.9496 \\
\hline$\geq 65$ Years $(\mathrm{N}=24)$ & $66.1 \%$ & \\
\hline \multicolumn{3}{|l|}{ Cell differentiation } \\
\hline Well $(\mathrm{N}=65)$ & $72.3 \%$ & 0.0170 \\
\hline Moderately \& poorly $(\mathrm{N}=34)$ & $49.2 \%$ & \\
\hline \multicolumn{3}{|l|}{ T Classification } \\
\hline Early stage $(\mathrm{T} 1, \mathrm{~T} 2, \mathrm{~N}=78)$ & $65.5 \%$ & 0.5279 \\
\hline Advanced stage $(\mathrm{T} 3, \mathrm{~T} 4, \mathrm{~N}=21)$ & $61.1 \%$ & \\
\hline \multicolumn{3}{|l|}{ Nodal classification } \\
\hline Negative $(\mathrm{N}=51)$ & $75.2 \%$ & 0.0110 \\
\hline Positive $(\mathrm{N}=48)$ & $52.6 \%$ & \\
\hline \multicolumn{3}{|l|}{ Stage (AJCC) } \\
\hline Early stage (stage I, II, N=45) & $72.1 \%$ & 0.0990 \\
\hline Advanced stage (stage III, IV, N=54) & $58.0 \%$ & \\
\hline \multicolumn{3}{|l|}{ Depth of invasion } \\
\hline$<4 \mathrm{~mm}(\mathrm{~N}=21)$ & $64.4 \%$ & 0.5701 \\
\hline$\geq 4 \mathrm{~mm}(\mathrm{~N}=78)$ & $62.1 \%$ & \\
\hline \multicolumn{3}{|l|}{ Resection margin } \\
\hline Clear $(\mathrm{N}=88)$ & $67.5 \%$ & 0.3489 \\
\hline Close \& positive $(\mathrm{N}=11)$ & $54.6 \%$ & \\
\hline \multicolumn{3}{|l|}{ Perineural invasion } \\
\hline Absent $(\mathrm{N}=86)$ & $67.9 \%$ & 0.3541 \\
\hline Present $(\mathrm{N}=13)$ & $53.9 \%$ & \\
\hline \multicolumn{3}{|l|}{ Lymphovascular invasion } \\
\hline Absent $(\mathrm{N}=93)$ & $65.3 \%$ & 0.3173 \\
\hline Present $(\mathrm{N}=6)$ & $50.0 \%$ & \\
\hline \multicolumn{3}{|l|}{ Extranodal extension } \\
\hline Absent $(\mathrm{N}=86)$ & $68.5 \%$ & 0.0035 \\
\hline Present $(\mathrm{N}=13)$ & $38.5 \%$ & \\
\hline \multicolumn{3}{|l|}{ Stabilin-2 intensity } \\
\hline Negative $(\mathrm{N}=70)$ & $74.1 \%$ & 0.0025 \\
\hline Positive $(\mathrm{N}=29)$ & $39.4 \%$ & \\
\hline \multicolumn{3}{|l|}{ Stabilin-2 reactivity } \\
\hline Negative $(<5 \%, \mathrm{~N}=35)$ & $77.0 \%$ & 0.0952 \\
\hline Positive $(\geq 5 \%, N=64)$ & $57.3 \%$ & \\
\hline \multicolumn{3}{|l|}{ Stabilin-2 IRS grade } \\
\hline Low $(\mathrm{N}=72)$ & $73.4 \%$ & 0.0027 \\
\hline Moderate \& high $(\mathrm{N}=27)$ & $40.0 \%$ & \\
\hline
\end{tabular}

AJCC: American Joint Committee on Cancer, IRS: immunoreactivity score.

CCL1/CCR8 and lymphatic endothelial cells control tumor cell entry into LNs and play an active role in several important biological events, including metastasis (2). However, the question remains whether tumor cells are entrapped by the sinusoidal endothelial cells of LNs. In the current study, we found that stabilin-2, adhesion molecule was expressed strongly in the sinusoidal endothelial cells of metastatic LN at the stage of micrometastasis. Because sinusoidal endothelial cells of LNs represent a barrier for entry of tumor cells into 
Table VI. Multivariate Cox regression analysis of disease-free survival in tongue cancer.

\begin{tabular}{lccc}
\hline & OR & $95 \%$ CI & $p$-Value \\
\hline Cell differentiation (well $v s$. moderate \& poor) & 1.759 & $0.877-3.525$ & 0.112 \\
Nodal classification (negative $v s$. positive) & 2.287 & $0.966-5.412$ & 0.050 \\
Extranodal extension (absent $v$. present) & 1.513 & $0.690-3.315$ & 0.301 \\
Stabilin-2 expression (low $v s$. moderate \& high) & 2.078 & $1.016-4.254$ & 0.045 \\
\hline
\end{tabular}

OR: Odds ratio, CI: confidence interval.

the LNs, these results indicate that stabilin-2 may play a role as a key molecule in the first entrapment step or initiation of $\mathrm{LN}$ metastasis in tongue cancer.

Stabilin-2 has been found to be highly expressed in sinusoidal endothelial cells of the spleen, liver, bone marrow, and LNs $(19,20)$. Loss of stabilin-2, a liver sinusoidal endothelial cell-specific marker, in peritumoral liver tissue of patients with hepatocellular carcinoma was significantly associated with increased survival, suggesting that loss of stabilin-2 may prevent interactions between endothelial and tumor cells (21). Systemic blockade of stabilin-2 was found to inhibit LN metastasis in an orthotopic prostate cancer model (22). Previously, we demonstrated that stabilin-2 mediated homophilic cell-cell interactions via its fasciclin 1 (FAS1) domains (13). Lymphatic endothelium expresses multiple integrin receptors, some of which play a role in tumor lymphangiogenesis and LN metastasis (23). Recently, activated integrin $\alpha 4 \beta 1$ was shown to act as an adhesive receptor that captures vascular cell adhesion molecule 1 (VCAM-1)-positive metastatic tumor cells, thereby promoting lymphatic metastasis (24). Our previous findings demonstrated that stabilin-2 was able to bind to several integrin receptors, such as M2 and v5 integrins $(9,17)$. In the present study, we show that expression of stabilin-2 in solid tumor specimens (tongue cancer, and lung, stomach, and colon cancer) resulted in increased lymphatic metastasis regardless of the cell types of tumors (squamous cell and adenocarcinoma) and all metastatic foci of LNs exhibited positive staining for stabilin2. However, stabilin-2-positive metastatic foci were observed in all LNs even if there was no expression of stabilin-2 in primary tumors. This may have been because we were unable to check the entire tumor specimens due to using tissue microarrays including only the invasive front of primary tumors. Based on previous information, the mechanism by which stabilin-2 mediates LN metastasis may be through stabilin-2-mediated homotypic interaction of tumor cells and LN. Thus, it is possible that stabilin-2-positive circulating tumor cells are captured in the lymphatic endothelium by integrin receptors, thereby promoting $\mathrm{LN}$ metastasis. Collectively, our results suggest that stabilin-2 can play a critical role in the first trapping step of LN metastasis through homotypic interaction with lymphatic endothelium.
In our study, nodal metastasis and stabilin-2 expression were independent risk factors of poorer DFS in tongue cancer after multivariate analysis. These results indicate that stabilin-2 may act as a biomarker predicting LN metastasis and tumor recurrence in tongue cancer. Thus, patients with stabilin-2-overexpressing tumors require more aggressive forms of adjuvant therapy, including systemic therapy.

In conclusion, to the best of our knowledge, this is the first report suggesting that stabilin-2 may play a critical role in the first entrapping step of $\mathrm{LN}$ metastasis through homotypic interaction with lymphatic endothelium. Stabilin-2 may be a tumor biomarker predicting LN metastasis in solid tumors and may provide insight into tumor biology, prognosis, and response to therapy in tongue cancer.

\section{Acknowledgements}

This study was funded by grants from the National Research Foundation of Korea (NRF-2015R1D1A1A01058348) and basic Science Research Program through the National Research Foundation of Korea (NRF) funded by the Ministry of Science, ICT and Future planning (NRF-2015R1A2A1A01003050 to SYK).

\section{References}

1 Kawada K and Taketo MM: Significance and mechanism of lymph node metastasis in cancer progression. Cancer Res 71: 1214-1218, 2011.

2 Das S, Sarrou E, Podgrabinska S, Cassella M, Mungamuri SK, Feirt N, Gordon R, Nagi CS, Wang Y, Entenberg D, Condeelis J and Skobe M: Tumor cell entry into the lymph node is controlled by CCL1 chemokine expressed by lymph node lymphatic sinuses. J Exp Med 210: 1509-1528, 2013.

3 Chandrasekaran S and King MR: Microenvironment of tumordraining lymph nodes: opportunities for liposome-based targeted therapy. Int J Mol Sci 15: 20209-20239, 2014.

4 Riabov V, Gudima A, Wang N, Mickley A, Orekhov A and Kzhyshkowska J: Role of tumor associated macrophages in tumor angiogenesis and lymphangiogenesis. Front Physiol 5: 75, 2014.

5 Wiley HE, Gonzalez EB, Maki W, Wu MT and Hwang ST: Expression of CC chemokine receptor-7 and regional lymph node metastasis of B16 murine melanoma. J Natl Cancer Inst 93: 1638-1643, 2001. 
6 Ding Y, Shimada Y, Maeda M, Kawabe A, Kaganoi J, Komoto I, Hashimoto $\mathrm{Y}$, Miyake $\mathrm{M}$, Hashida $\mathrm{H}$ and Imamura $\mathrm{M}$ : Association of CC chemokine receptor 7 with lymph node metastasis of esophageal squamous cell carcinoma. Clin Cancer Res 9: 3406-3412, 2003.

7 D'Souza S, Park SY and Kim IS: Stabilin-2 acts as an engulfment receptor for the phosphatidylserine-dependent clearance of primary necrotic cells. Biochem Biophys Res Commun 432: 412-417, 2013.

8 Park SY, Jung MY, Kim HJ, Lee SJ, Kim SY, Lee BH, Kwon TH, Park RW and Kim IS: Rapid cell corpse clearance by stabilin-2, a membrane phosphatidylserine receptor. Cell Death Differ 15: 192-201, 2008.

9 Jung MY, Park SY and Kim IS: Stabilin-2 is involved in lymphocyte adhesion to the hepatic sinusoidal endothelium via the interaction with alphaMbeta2 integrin. J Leukoc Biol 82: 1156-1165, 2007.

10 Lee SJ, So IS, Park SY and Kim IS: Thymosin beta4 is involved in stabilin-2-mediated apoptotic cell engulfment. FEBS Lett 582: 2161-2166, 2008.

11 Park SY, Kang KB, Thapa N, Kim SY, Lee SJ and Kim IS: Requirement of adaptor protein GULP during stabilin-2mediated cell corpse engulfment. J Biol Chem 283: 1059310600, 2008.

12 Park SY, Kim SY, Jung MY, Bae DJ and Kim IS: Epidermal growth factor-like domain repeat of stabilin-2 recognizes phosphatidylserine during cell corpse clearance. Mol Cell Biol 28: 5288-5298, 2008.

13 Park SY, Jung MY and Kim IS: Stabilin-2 mediates homophilic cell-cell interactions via its FAS1 domains. FEBS Lett 583: 1375-1380, 2009.

14 Kim S, Bae DJ, Hong M, Park SY and Kim IS: The conserved histidine in epidermal growth factor-like domains of stabilin-2 modulates $\mathrm{pH}$-dependent recognition of phosphatidylserine in apoptotic cells. Int J Biochem Cell Biol 42: 1154-1163, 2010.

15 Lee GY, Kim JH, Oh GT, Lee BH, Kwon IC and Kim IS: Molecular targeting of atherosclerotic plaques by a stabilin-2specific peptide ligand. J Control Release 155: 211-217, 2011.

16 Lee SJ, Park SY, Jung MY, Bae SM and Kim IS: Mechanism for phosphatidylserine-dependent erythrophagocytosis in mouse liver. Blood 117: 5215-5223, 2011.

17 Kim S, Park SY, Kim SY, Bae DJ, Pyo JH, Hong M and Kim IS: Cross talk between engulfment receptors stabilin-2 and integrin $\alpha v \beta 5$ orchestrates engulfment of phosphatidylserineexposed erythrocytes. Mol Cell Biol 32: 2698-2708, 2012.
18 Hirose Y, Saijou E, Sugano Y, Takeshita F, Nishimura S, Nonaka H, Chen YR, Sekine K, Kido T, Nakamura T, Kato S, Kanke T, Nakamura K, Nagai R, Ochiya T and Miyajima A: Inhibition of stabilin-2 elevates circulating hyaluronic acid levels and prevents tumor metastasis. Proc Natl Acad Sci USA 109: 4263-4268, 2012.

19 Zhou B, Weigel JA, Fauss L and Weigel PH: Identification of the hyaluronan receptor for endocytosis (HARE). J Biol Chem 275: 37733-37741, 2000.

20 Martens JH, Kzhyshkowska J, Falkowski-Hansen M, Schledzewski K, Gratchev A, Mansmann U, Schmuttermaier C, Dippel E, Koenen W, Riedel F, Sankala M, Tryggvason K, Kobzik L, Moldenhauer G, Arnold B and Goerdt S: Differential expression of a gene signature for scavenger/lectin receptors by endothelial cells and macrophages in human lymph node sinuses, the primary sites of regional metastasis. J Pathol 208: 574-589, 2006.

21 Geraud C, Mogler C, Runge A, Evdokimov K, Lu S, Schledzewski K, Arnold B, Hammerling G, Koch PS, Breuhahn K, Longerich T, Marx A, Weiss C, Damm F, Schmieder A, Schirmacher P, Augustin HG and Goerdt S: Endothelial transdifferentiation in hepatocellular carcinoma: loss of stabilin2 expression in peri-tumourous liver correlates with increased survival. Liver Int 33: 1428-1440, 2013.

22 Simpson MA, Weigel JA and Weigel PH: Systemic blockade of the hyaluronan receptor for endocytosis prevents lymph node metastasis of prostate cancer. Int J Cancer 131: E836-840, 2012.

23 Chen J, Alexander JS and Orr AW: Integrins and their extracellular matrix ligands in lymphangiogenesis and lymph node metastasis. Int J Cell Biol 2012: 853703, 2012.

24 Garmy-Susini B, Avraamides CJ, Desgrosellier JS, Schmid MC, Foubert P, Ellies LG, Lowy AM, Blair SL, Vandenberg SR, Datnow B, Wang HY, Cheresh DA and Varner J: PI3K $\alpha$ activates integrin $\alpha 4 \beta 1$ to establish a metastatic niche in lymph nodes. Proc Natl Acad Sci USA 110: 9042-9047, 2013.

Received October 11, 2016

Revised October 27, 2016

Accepted November 4, 2016 